\title{
On the use of cyanine dyes as low-bandgap materials in bulk heterojunction photovoltaic devices
}

\author{
Fernando A. Castro ${ }^{\mathrm{a}, \mathrm{b}}$, Antonin Faes ${ }^{\mathrm{a}}$, Thomas Geiger ${ }^{\mathrm{a}}$, Carlos F.O. Graeff ${ }^{\mathrm{b}}$, \\ Matthias Nagel ${ }^{\mathrm{a}}$, Frank Nüesch ${ }^{\mathrm{a}}$, Roland Hany ${ }^{\mathrm{a}, *}$ \\ a Empa, Swiss Federal Laboratories for Materials Testing and Research, Laboratory for Functional Polymers, \\ Überlandstr. 129, CH-8600 Dübendorf, Switzerland \\ ${ }^{\mathrm{b}}$ Departemento de Fisica e Matemática-Faculdade de Filosofia, Ciências e Letras de Ribeirão Preto-Universidade de São Paulo, \\ Av. Bandeirantes 3900, 14040-901 Ribeirão Preto-SP, Brazil \\ Received 19 January 2006; accepted 21 June 2006 \\ Available online 31 July 2006
}

\begin{abstract}
Cyanine dyes with absorption edges of almost $1000 \mathrm{~nm}$ were used in combination with MEH-PPV for the fabrication of organic solar cells. For blended thin films, a pronounced phase separation between the two components occurred and resulted in photocurrents with different signs for bilayer and bulk heterojunction devices. Absorption spectra and selective dissolution experiments were used to illustrate the process of vertical phase segregation, with the preferential wetting of the polar anode by the cyanines while maintaining percolating carrier pathways between the electrodes. For a cyanine with long alkyl side chains, the compatibility with the polymer matrix was increased and the development of the effective inverted bilayer configuration was not observed. The generally low oxidative photocurrents were explained with unfavourable shifts of the highest occupied molecular orbital (HOMO) dye energy levels in the solid state.
\end{abstract}

(C) 2006 Elsevier B.V. All rights reserved.

Keywords: Organic solar cell; Cyanine dye; Photovoltaic cell

\section{Introduction}

The possibility for the direct conversion of light into electrical current using organic semiconducting materials has attracted much interest during the last years [1]. State-of-the-art organic solar cells make use of a combination of an electron-donor and an electron-acceptor material with suitable redox energy levels, sandwiched as a thin film between a hole- and an electronaccepting electrode [2-6]. The materials can be deposited one by one or are applied as a blend.

The planar geometrical interface of the bilayer heterojunction cell [4] is not optimized for charge generation, since only those photons that are absorbed within the exciton diffusion length $(10-40 \mathrm{~nm})[3,4]$ of the interface will create free charge carriers. However, the created charges are spatially separated and confined to the acceptor and donor sites of the interface, and charge recombination is reduced.

* Corresponding author. Tel.: +41 44 8234084; fax: +41 448234012.

E-mail address: roland.hany@empa.ch (R. Hany).
The interpenetrating network architecture of the blend (bulk) heterojunction cell is designed for efficient exciton dissociation [2]. However, the charges must be transported to the respective electrodes as well, which requires selective percolating paths for hole and electron transport. Indeed, the prediction and control of the microstructure in dispersed heterojunctions is a complex problem depending on solid-state miscibility, aggregate formation and uncontrollable phase separation of the two materials [7]. The challenge is to fine tune the blend morphology at the nanometer scale, to achieve a demixing in such a way that the material interface area is maximized, with dimensions of phase separation within the exciton diffusion range and continuous pathways for transport of charges to the electrodes at the same time. This critical issue is being addressed increasingly [2,8-12], and inventive device concepts try to combine the high efficiency of charge generation of the bulk with the low resistance to charge transport of the planar heterojunction in single device configurations $[3,6]$,

Another focus of attention in the research on organic solar cells is the development of materials that harvest more photons at long wavelengths. This is because most popular organic solar 
1ls [13] are based on materials that absorb light primarily in e ultraviolet and visible region, and a further increase in effiency requires novel low-bandgap compounds to increase the otocurrent [14].

In this connection, cyanine dyes have attracted attention as tive components for optoelectronic applications [15-21]. Cyanes are a class of symmetrically, charged, all-E-configurated lymethine dyes. They generally show a very strong $\pi-\pi^{*}$ sorption, which can be tuned through the visible and nearfrared region by varying the length of the polymethine ain. It has recently been demonstrated that cyanine dyes $\mathrm{n}$ act both as donors and acceptors in bilayer heterojuncin photovoltaic devices [22], and a long-wavelength absorb$\mathrm{g}$ cyanine dye has been used with a cyanine-fullerene dyad produce photocurrent up to $800 \mathrm{~nm}$ in multilayer devices 3].

In this work, we examined the applicability of cyanine dyes as ectron acceptors, in combination with MEH-PPV as the elecn donor polymer, in bulk heterojunction photovoltaic devices. anine dyes with different redox levels were used to investite the influence of frontier molecular orbital energies on the terogeneous charge transfer process. At the same time, the gths of alkyl side chains were varied to affect the compatility between the donor and acceptor matrix. We compared the rformance of blended with bilayer devices and explain the pearance of an inverted bilayer configuration for blend films th high cyanine loading.

\section{Experimental}

MEH-PPV with an average molecular weight of $M_{\mathrm{n}}=40000$ 70000 was purchased from Aldrich. Cyanine dye CyA (Fig. 1a) was purchased from Synthon Chemicals, Germany, and recrystallized from ethylacetate before use, cyanine dyes CyBs and CyBl (Fig. 1a) were synthesized in our laboratory. Perchlorate was the counter anion for all three dyes. ${ }^{1} \mathrm{H}-\mathrm{NMR}$ data for $\mathrm{CyBs}$ (DMSO-d $\left.{ }_{6}\right): 1.38 \mathrm{ppm}(6 \mathrm{H}, \mathrm{t}, J=7.2 \mathrm{~Hz}) ; 1.90 \mathrm{ppm}(2 \mathrm{H}, \mathrm{m})$; $1.96 \mathrm{ppm}(12 \mathrm{H}, \mathrm{s}) ; 2.77 \mathrm{ppm}(4 \mathrm{H}, \mathrm{t}, J=5.9 \mathrm{~Hz}) ; 4.39 \mathrm{ppm}(4 \mathrm{H}$, q, $J=7.2 \mathrm{~Hz}) ; 6.37 \mathrm{ppm}(2 \mathrm{H}, \mathrm{d}, J=14.3 \mathrm{~Hz}) ; 7.4-8.5 \mathrm{ppm}(14 \mathrm{H})$. CyBl (DMSO-d $\left.{ }_{6}\right): 0.80 \mathrm{ppm}(6 \mathrm{H}, \mathrm{t}, J=7.1 \mathrm{~Hz}) ; 1.12-1.47 \mathrm{ppm}$ $(60 \mathrm{H}, \mathrm{m}) ; 1.79 \mathrm{ppm}(4 \mathrm{H}, \mathrm{m}) ; 1.90 \mathrm{ppm}(2 \mathrm{H}, \mathrm{m}) ; 1.95 \mathrm{ppm}$ $(12 \mathrm{H}, \mathrm{s}) ; 2.73 \mathrm{ppm}(4 \mathrm{H}, \mathrm{t}, J=5.9 \mathrm{~Hz}) ; 4.34 \mathrm{ppm}(4 \mathrm{H}, \mathrm{t}$, $J=6.8 \mathrm{~Hz}) ; 6.35 \mathrm{ppm}(2 \mathrm{H}, \mathrm{d}, J=14.2 \mathrm{~Hz}) ; 7.4-8.5 \mathrm{ppm}(14 \mathrm{H})$. PEDOT:PSS (from Bayer), chlorobenzene (from Fluka) and 2,2,3,3-tetrafluoro-l-propanol (TFP, from Fluka) were used as received.

The redox potentials of the cyanine dyes were measured in solution by cyclic voltammetry using an Autolab potentiostat and a standard three electrodes cell. Measurements were performed in acetonitrile solution using tetrabutylammonium perchlorate $(0.1 \mathrm{~mol} / \mathrm{L})$ as supporting electrolyte, a glassy carbon rotating disk $(0.3 \mathrm{~cm}$ in diameter) as working electrode and a glassy carbon wire as counter electrode. Potentials were measured versus a $3 \mathrm{M} \mathrm{KC} 1 \mathrm{Ag} / \mathrm{AgCl}$ doublejunction reference electrode and were calibrated against a $\mathrm{Ru}(\mathrm{bpy}){ }_{3}{ }^{\mathrm{nt}}$ reference. To

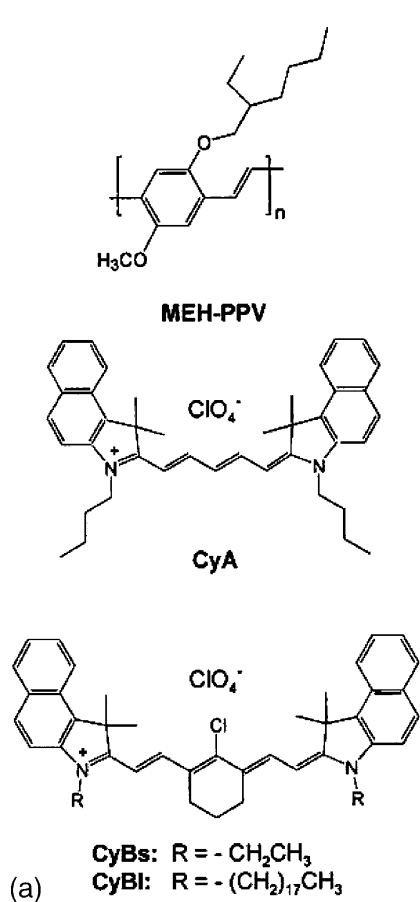

(a)

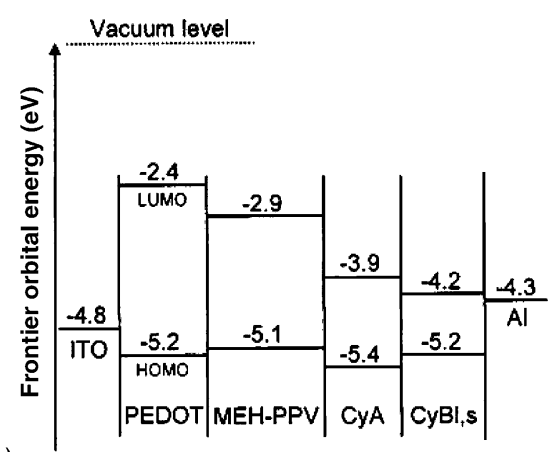

(b)

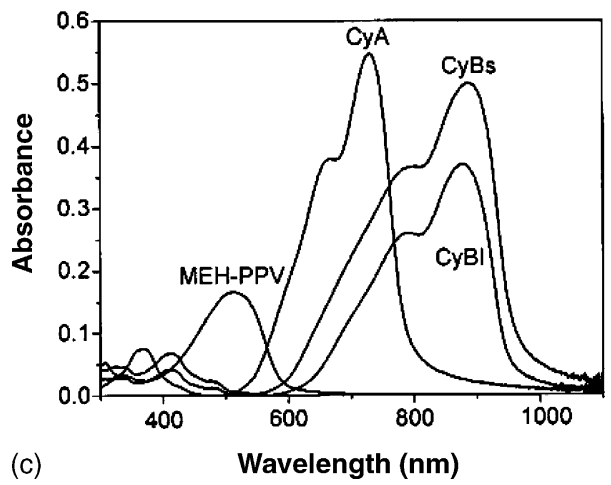


relate the electrochemical values to the physical scale, the value of $-4.70 \mathrm{eV}$ versus vacuum was taken for the $\mathrm{Ag} / \mathrm{AgCl}$ reference [24]. The highest occupied molecular orbital (HOMO) and lowest unoccupied molecular orbital (LUMO) energy levels of MEH-PPV and PEDOT were adopted from the literature $[4,21]$.

Photovoltaic devices were fabricated on ITO-coated glass from Merck with a sheet resistance of $30 \Omega$ /square. In every case, a $90 \mathrm{~nm}$ thick PEDOT layer was first spin-coated $(60 \mathrm{~s}$ at $2000 \mathrm{rpm}$ ) onto the anode. After heating at $120^{\circ} \mathrm{C}$ under vacuum for $90 \mathrm{~min}$, the substrates were transferred to a nitrogenfilled glove box. For planar bilayer devices, a MEH-PPV film with a thickness of approximately $20 \mathrm{~nm}$ was then spin-coated (120 s at $1500 \mathrm{rpm}$ ) from a $5 \mathrm{mg} / \mathrm{mL}$ chlorobenzene solution onto PEDOT. On top of this thin film, the cyanine layers were spincoated $(60 \mathrm{~s}$ at $1500 \mathrm{rpm})$ with a thickness of $45-50 \mathrm{~nm}$ from a solution of $5 \mathrm{mg}$ of CyA, CyBs or CyBl dissolved in $1 \mathrm{~mL}$ of a solvent mixture of TFP:chlorobenzene $=6: 1$ by volume. Blended films with a thickness of 70-100 nm were prepared by mixing together different quantities of stock solutions of MEHPPV $(10 \mathrm{mg} / \mathrm{mL}$ chlorobenzene) and cyanine dye $(10 \mathrm{mg} / \mathrm{mL}$ of TFP: chlorobenzene $=1: 50$ ) before spin-coating. Finally, a $50 \mathrm{~nm}$ thick aluminium cathode layer was thermally deposited under high vacuum $\left(<3 \times 10^{-6}\right.$ mbar $)$ to form active device areas of 0.07 or $0.03 \mathrm{~cm}^{2}$, respectively. Film thicknesses were measured with an Ambios Technology XP-1 surface profilometer. The finished solar cells were stored and subsequently analyzed in a $\mathrm{N}_{2}$ atmosphere. The spectrally resolved photocurrents under short-circuit conditions were measured using a monochromator with a xenon lamp light source having an irradiation intensity of approximately $5 \mathrm{~mW} / \mathrm{cm}^{2}$ at $500 \mathrm{~nm}$. Open-circuit voltages under white light were obtained using a Keithley 2400 sourcemeasure unit.

\section{Results and discussion}

Fig. 1a shows the chemical structures of the electron donor polymer, MEH-PPV, and of the electron acceptor cyanine dyes used in this study. The energy levels of the frontier molecular orbitals are summarized in Fig. 1b, and Fig. 1c shows absorption spectra of thin films as they were used for the bilayer heterojunction configurations. $\mathrm{CyA}$ and $\mathrm{CyBs}, 1$ were chosen to vary the electron acceptor redox levels, and cyanines $\mathrm{CyB}$ with short (CyBs) and long ( $\mathrm{CyBl}$ ) alkyl side chains were applied to possibly affect the compatibility between the ionic dyes and the relatively apolar MEH-PPV polymer matrix.

The absorption spectra of Fig. 1c show that the absorptions of MEH-PPV and the cyanine dyes are complementary, allowing to harvest photons in a broad spectral domain ranging from $400 \mathrm{~nm}$ up to $1000 \mathrm{~nm}$. The exciton diffusion length of MEH-PPV is $13 \mathrm{~nm}$ [4], and we therefore limited the polymer film thickness in the bilayer configuration to approximately $20 \mathrm{~nm}$. The cyanine film thicknesses were 45-49 nm, and the absorption maxima are at $731 \mathrm{~nm}$ for CyA, and at $878 \mathrm{~nm}$ and $877 \mathrm{~nm}$ for CyBs and $\mathrm{CyB}$, respectively. The optical densities of $>0.35$ at these wavelengths underline the strong light absorption of cyanine dyes. We measured extinction coefficients $(\mathrm{L} / \mathrm{mol} \mathrm{cm})$ in methanol solutions of $\varepsilon(680 \mathrm{~nm})=190,000$ for CyA, $\varepsilon(815)=270,000$ for CyBs, and $\varepsilon(820)=260,000$ for CyBl. Due to aggregation and polarization effects [23], the absorption maxima are shifted by more than $50 \mathrm{~nm}$ to longer wavelengths in the solid state. The absorption maximum of MEH-PPV in the film at $514 \mathrm{~nm}$ differed only slightly from the one in solution, being at $506 \mathrm{~nm}$ when dissolved in chlorobenzene.

Fig. 2 shows spectrally resolved photocurrent spectra for bilayer and bulk photovoltaic devices of MEH-PPV/CyA (Fig. 2a) and MEH-PPV/CyBl (Fig. 2b) at short circuit conditions. For the bilayer CyA device, the current density at $500 \mathrm{~nm}$ is $-1.2 \mu \mathrm{A} / \mathrm{cm}^{2}$, and a low photocurrent at longer wavelengths, where CyA absorbs, is observed. For blends with increasing cyanine dye concentration, the photocurrent in the MEH-PPV absorption region first decreases, then changes the sign, and is $+0.8 \mu \mathrm{A} / \mathrm{cm}^{2}$ for a blend with $70 \mathrm{wt} \%$ of CyA. Very small photocurrents at wavelengths $>600 \mathrm{~nm}$ were measured for the blend devices. Results for MEH-PPV/CyBs devices were similar, with photocurrents in the 400-600 $\mathrm{nm}$ region of approximately double intensities as for CyA, and negligible currents at longer wavelengths for all cells (data not shown). We also note that solar cells made with MEH-PPV monolayers only showed photocurrents with maxima of $<0.03 \mu \mathrm{A} / \mathrm{cm}^{2}$, and that dark currents in the -0.5 to $+1 \mathrm{~V}$ range were always $<0.01 \mu \mathrm{A} / \mathrm{cm}^{2}$.

The photocurrent spectra of Fig. 2a demonstrate the reductive charge transfer process after photoexcitation of MEH-PPV.
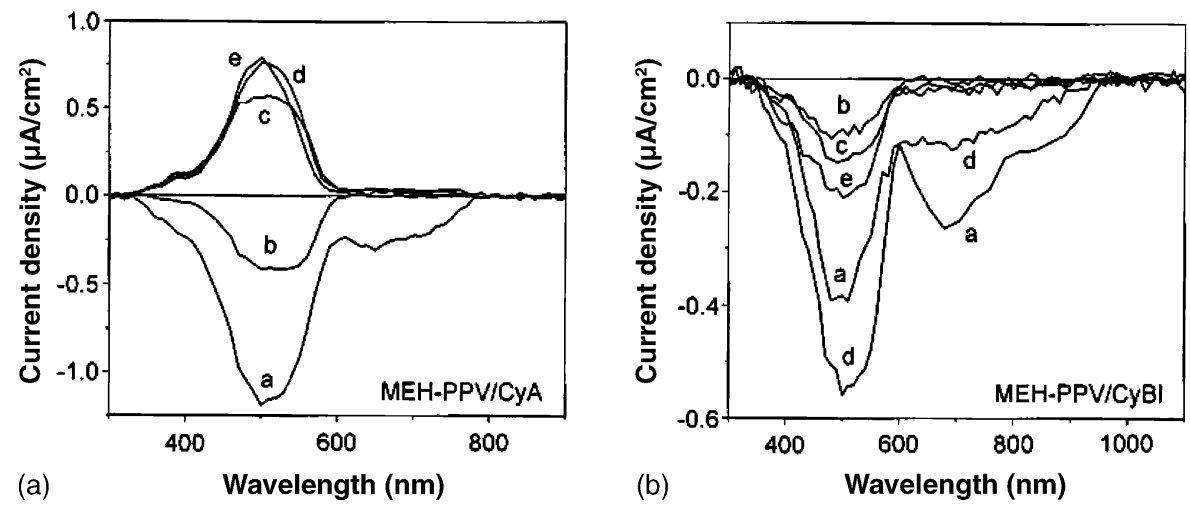

Fig. 2. Short-circuit photocurrent spectra of (a) MEH-PPV/CyA and (b) MEH-PPV/CyBl photovoltaic devices. Letter a denotes a planar bilayer configuration, and -e are results from blended devices with $15,30,50$, and $70 \mathrm{wt} \%$ of cyanine, respectively. 
e energy differences between the LUMO levels of MEH-PPV $\mathrm{d}$ CyA or CyBs are sufficiently large $(>1 \mathrm{eV})$ to overcome the citon binding energy [25], and efficient exciton dissociation donor-acceptor heterointerfaces can take place. On the other nd, the oxidative charge transfer, that is, the initial photocurat generation process after excitation of the electron acceptors, unfavourable for CyA, and not allowed for CyBs at all. This $n$ be explained by the small energy differences between the OMO levels of the donor and acceptor materials. These difcences are $0.3 \mathrm{eV}$ for MEH-PPV/CyA, and only $0.1 \mathrm{eV}$ for $\mathrm{EH}-\mathrm{PPV} / \mathrm{CyBs}$, and the driving force for electron transfer is all [3]. We also note that the frontier orbital energies of Fig. 1b ere obtained from cyclic voltammetry measurements in solu$\mathrm{n}$, and these values lose their absolute meaning for the electron insfer phenomena in the solid state. This is because the polarand specific intermolecular interactions of the cyanine dyes solution are markedly different from those in the solid state, $\mathrm{d}$ the redshifts of the absorbance maxima (see above) must be companied by cooperative upward or downward shifts of the anine HOMO and LUMO levels in the photovoltaic devices. e cannot completely rule out the alternative possibility that all exciton diffusion coefficients of CyA and CyBs impose trong limit of the fraction of cyanine excitons reaching the terointerface. However, cyanines are known to be efficient ectron donors in combination with $\mathrm{C}_{60}$ [21-23], Therefore, conclude it is rather the small energy difference between HOMO donor and acceptor levels that prevent the efficient idative electron transfer, and that the exciton diffusion ranges $\mathrm{CyA}$ and $\mathrm{CyBs}$ are not current limiting. An additional conbution to the photocurrent at long wavelengths might come $\mathrm{m}$ exciton dissociation at the cyanine/Al interface. This would plain the fact that an oxidative photocurrent was observed for MEH-PPV/CyA bilayer configuration only (Fig. 2a).

Substantial photocurrents in the CyA and CyBs absorption gions necessitate cyanines with lower HOMO energy levels. e balanced design of the molecular frontier orbital levels is nerally a challenge when using low-bandgap materials, in der to maintain both the efficiency of charge generation and gh open-circuit voltage at the same time $[7,14]$. If both elecon transfer reactions take place and assuming complete photon sorption, the absorption edge of almost $1000 \mathrm{~nm}$ for CyBs, 1 sults in potentially high photocurrents since more than $80 \%$ the incoming solar light is harvested [26]. On the other hand, heterojunction photovoltaic devices the open-circuit voltage, c, is related to the energy difference between the HOMO of e donor and the LUMO of the acceptor [1,7]. It follows that e relative frontier energy levels should be adjusted in such a yy that both materials contribute to the photocurrent, but not be osen too different such that the charge generation processes ke place at the expense of a decreased $V_{\mathrm{oc}}$.

The sign inversion of the photocurrent when comparing layer with blended MEH-PPV/CyA (or CyBs) solar cells an unusual observation (Fig. 2a). We explain this phemenon by a demixing process during spin-coating of the ended films, accompanied by a surface-oriented phase sepation which leads to the aggregation of the cyanines at the lar PEDOT surface $[9,27]$. Indeed, cyanine dyes are ionic molecules and blends with MEH-PPV are likely to be strongly incompatible. For low cyanine concentrations, they segregate and form embedded clusters in the MEH-PPV matrix. The carrier-conducting pathways then contain bottlenecks acting as traps, which leads to increased charge recombination and loss of current. Reduced photocurrents for low dye contents are therefore expected. For increasing dye concentrations, vertical phase segregation starts with the preferential wetting of the polar anode surface by the cyanines. The device gradually changes from a bilayer ITO/PEDOT/MEH-PPV/CyA/Al structure to an ITO/PEDOT/CyA/MEH-PPV/Al configuration. This has the effect of enabling internal currents to flow locally within different parts of the device with low external current for intermediate cyanine dye concentrations. Finally, the inverted morphology predominates and the sign of the photocurrents changes for blended devices with high acceptor concentrations.

We also confirmed the necessity that the changing morphology must be accompanied by a sign inversion of $V_{\mathrm{oc}}$, and measured $V_{\mathrm{oc}}=0.63 \mathrm{~V}$ for the CyA bilayer device using white-light irradiation $\left(\sim 0.25 \mathrm{~W} / \mathrm{cm}^{2}\right)$, and $V_{\text {oc }}=-0.27 \mathrm{~V}$ for the $70 \mathrm{wt} \%$ blend. For CyBs, $V_{\text {oc }}$ was $0.79 \mathrm{~V}$ for the bilayer cell, and $V_{\mathrm{oc}}=0.33,-0.24,-0.38,-0.27 \mathrm{~V}$ were measured for CyBs blends with increasing cyanine concentrations. The opencircuit voltages of the blends are lower than those of the bilayer device. This indicates the occurrence for direct paths between the cathode and anode in the blended devices [5], predominantly consisting of MEH-PPV for low acceptor concentrations, and of cyanines for high concentrations. Evidence for such percolating carrier pathways was obtained from selective dissolution experiments of photovoltaic devices with tetrafluoropropanol (see below).

Extending the dye side chains from ethyl in CyBs to octadecyl in CyBl (Fig. 1a) increased the compatibility with the donor polymer. The phase separation process and wetting of the anode during spin-coating was therefore not as pronounced as for the more polar $\mathrm{CyA}$ and $\mathrm{CyBs}$ components, and photocurrents of bilayer and blend devices of MEH-PPV/CyBl have always the same sign (Fig. 2b). In the MEH-PPV absorption region, currents of blended cells are low both for low and high dye concentrations, and pass through a maximum for the $50 \mathrm{wt} \%$ sample. At the same time, a relative increase of photocurrents in the cyanine dye absorption region is observed. For this material combination both the reductive and oxidative electron transfer reactions are therefore allowed. This indicates that the redox levels of $\mathrm{CyBl}$ in the solid state more likely shifted to lower energies, in contrast to CyBs. This relative shift also means that the energy difference between the HOMO of MEH-PPV and the LUMO level of $\mathrm{CyBl}$ is lowered. As explained above, this should be reflected in a reduction of the open-circuit voltage. Indeed, $V_{\mathrm{oc}}$ was $0.34 \mathrm{~V}$ for the $\mathrm{CyBl}$ bilayer device only, considerable less than then values of $0.63 \mathrm{~V}$ for $\mathrm{CyA}$ and $0.79 \mathrm{~V}$ for CyBs.

The current densities for $\mathrm{CyBl}$ blend devices are lower than for $\mathrm{CyA}$ (and $\mathrm{CyBs}$ ), although the more homogeneous dispersion of $\mathrm{CyBl}$ in blend devices facilitates exciton dissociation and charge generation, the necessary first step to obtain a photocurrent (Fig. 2a and b). Also, the efficiency of the bilayer cell is reduced by about a factor of three. This supports the fact 

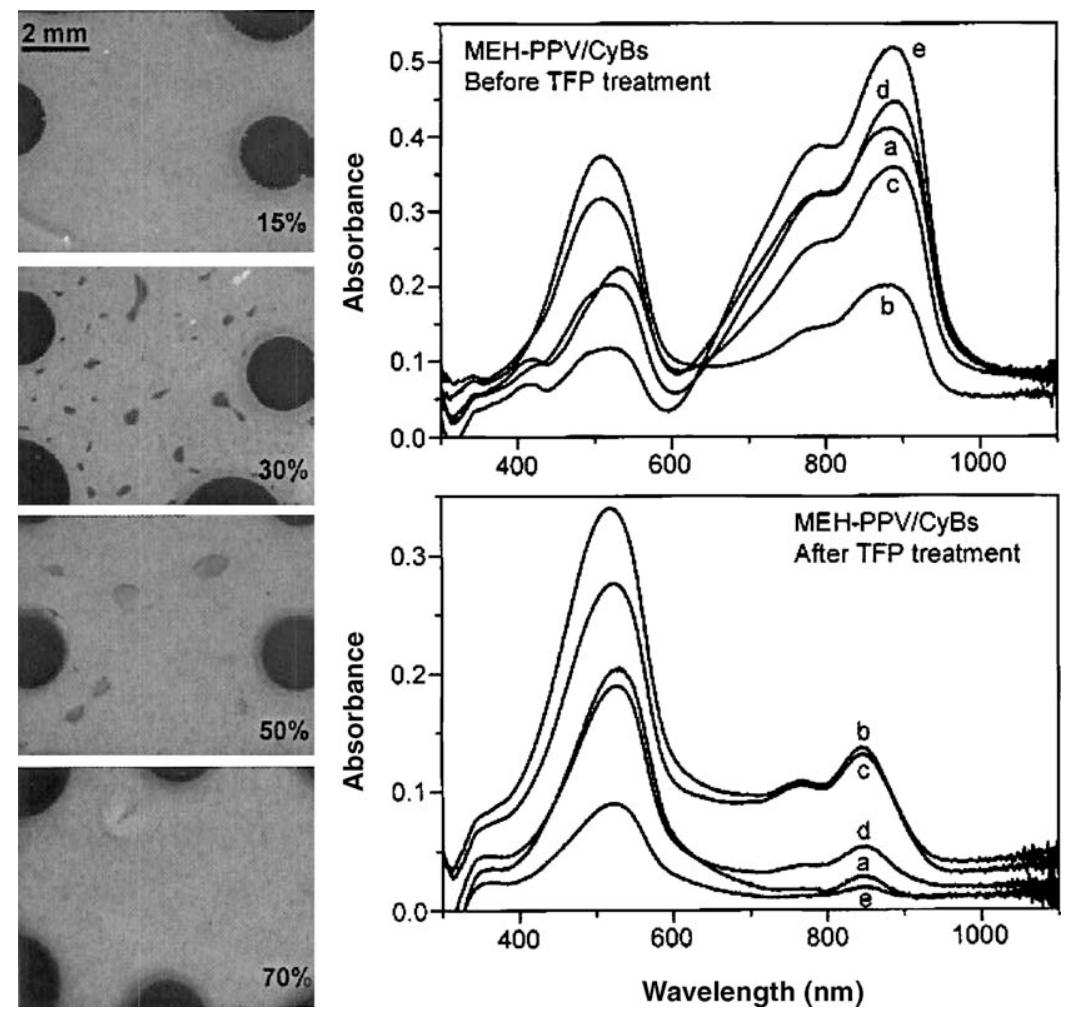

Fig. 3. Left: optical microscope pictures of MEH-PPV/CyBs bulk heterojunction photovoltaic devices after immersion for 2 min in 2,2,3,3-tetrafluoro-1-propanol (TFP). The black circles with diameters of 0.2 or $0.3 \mathrm{~cm}$ represent the aluminium cathode. Right: absorption spectra before and after TFP treatment. Letter a denotes the bilayer configuration, and $\mathbf{b}-\mathbf{e}$ are results from blended devices with $15,30,50$, and $70 \mathrm{wt} \%$ of cyanine, respectively.

that a fine scale of phase separation in the blend is not the only criterion to obtain high photosensitivity, and it is known that too intimate mixing between the two components can lead to reduced charge collection due to small charge mobilities and non-connected islands which act as charge trap centers [5,7]. The long alkyl side chains in $\mathrm{CyBl}$ also increase the distance between cyanine cores, leading to inefficient electron transfer through the acceptor phase. This might explain the lower photocurrent for the CyBl bilayer device [11].

To confirm the proposed morphology of blended films, cells were immersed for $2 \mathrm{~min}$ in 2,2,3,3-tetrafluoro-1-propanol (TFP), a selective solvent for cyanines. Solvent-treated films were then visually inspected and UV spectroscopy was used to optically detect the dye left in the film. Fig. 3 shows absorption spectra of original CyBs devices and after TFP treatment together with the corresponding optical microscope pictures.

The absorbances in the MEH-PPV region (400-600 nm) remain constant, which proves the selectivity of TFP and shows that the thin films were not simply peeled off mechanically during the immersion in the solvent. CyBs in the bilayer structure was dissolved completely and the absorbance at $880 \mathrm{~nm}$ decreases from approximately 0.4 (before) to less than 0.02 (after TFP treatment). For blended films, the change in absorption was opposite from what was expected. The relative decrease is less than a factor of two for low cyanine contents, whereas for high concentrations, the dyes were completely dissolved. For small contents, cyanine dye aggregates are formed that are embedded in the polymer matrix and therefore not accessible to TFP. For high concentrations, a wetting layer covers the anode, however, with percolating paths for the cyanines between the two electrodes at the same time. This allows TFP to penetrate the film and to effectively rinse out the cyanine molecules.

Microscope pictures of blend devices after TFP treatment illustrate this sequence (Fig. 3). For the $15 \mathrm{wt} \%$ sample the cyanine aggregates are small and the film appears unstructured. The same is true for the $70 \%$ sample, however, because in this case the cyanine was completely removed by TFP. For the intermediate devices, embedded dye aggregates with sizes up to $0.1 \mathrm{~cm}$ are clearly visible. This scale of phase separation is orders of magnitude larger than what is usually dealt with in blended thin films $[9,10,12]$ and again reflects the strong incompatibility between CyBs and MEH-PPV. Similar observations were made for CyA. Finally, for CyBl devices, all films appeared unstructured looked at by optical microscopy, in agreement with the better miscibility between the two components and the finer scale of phase separation in the blended films.

\section{Conclusion}

The observed morphologies and the scale of phase-separated structures in blended films can be attributed to the ionic nature of the cyanines. These effects are unlikely to be restricted to MEHPPV. Rather, they may occur with other popular electron donor polymers, such as poly(3-hexylthiophene), as well. However, the spatially distribution can be tuned by varying the cyanine substituents, and the vertical phase segregation phenomenon could 
exploited to produce layered spin-coated films when selective lvents are not available. To produce efficient bulk heterojuncin photovoltaic devices with small cyanine dye molecules, suggest that semiconducting, conjugated polyelectrolytes the anionic electron donor counterparts might be a concepal solution. We are also synthesizing cyanine polymers and nor-cyanine acceptor diblock copolymers. Such systems are own to self-organize with domain sizes down to the nanometre ale, and thus allow the controlled arrangement of the biphase twork to balance exciton dissociation and charge transport quirements.

\section{ferences}

] C.J. Brabec, Solar Energy Mater. Solar Cells 83 (2004) 273.

S.E. Shaheen, C.J. Brabec, N.S. Sariciftci, F. Padinger, T. Fromherz, J.C. Hummelen, Appl. Phys. Lett. 78 (2001) 841.

] J. Xue, B.P. Rand, S. Uchida, S.R. Forrest, Adv. Mater. 17 (2005) 66.

] M.M. Alam, S.A. Jenekhe, Chem. Mater. 16 (2004) 4647.

] H.J. Snaith, N.C. Greenham, R.H. Friend, Adv. Mater. 16 (2004) 1640.

] F. Yang, M. Shtein, S.R. Forrest, Nature Mater. 4 (2005) 37.

'] H. Hoppe, N.S. Sariciftci, J. Mater. Res. 19 (2004) 1924.

] A. Ltaief, J. Davenas, A. Bouazizi, R.B. Chaâbane, P. Alcouffe, H.B. Ouada, Mater. Sci. Eng. C25 (2005) 67.

] J. Chappell, D.G. Lidzey, P.C. Jukes, A.M. Higgins, R.L. Thompson, S. O'Connor, I. Grizzi, R. Fletcher, J. O'Brien, M. Geoghegan, R.A.L. Jones, Nature Mater. 2 (2003) 616.

] X. Yang, J. Loos, S.C. Veenstra, W.J.H. Verhees, M.M. Wienk, J.M. Kroon, M.A.J. Michels, R.A.J. Janssen, Nano Lett. 5 (2005) 579.
[11] L. Zheng, Q. Zhou, X. Deng, W. Fei, N. Bin, Z.-X. Guo, G. Yu, Y. Cao, Thin Solid Films 489 (2005) 251.

[12] H. Hoppe, M. Niggemann, C. Winder, J. Kraut, R. Hiesgen, A. Hinsch, D. Meissner, N.S. Sariciftci, Adv. Funct. Mater. 14 (2004) 1005.

[13] G. Li, V. Shrotriya, J. Huang, Y. Yao, T. Moriarty, K. Emery, Y. Yang, Nature Mater. 4 (2005) 864.

[14] F. Zhang, E. Perzon, X. Wang, W. Mammo, M.R. Andersson, O. Inganas, Adv. Funct. Mater. 15 (2005) 745.

[15] K. Takazawa, Y. Kitahama, Y. Kimura, G. Kido, Nano Lett. 5 (2005) 1293.

[16] S. Bourbon, M. Gao, S. Kirstein, Syn. Metals 101 (1999) 152.

[17] E.I. Mal'tsev, D.A. Lypenko, V.V. Bobinkin, B.I. Shapiro, A.R. Tameev, A.I. Tolmachev, Y.L. Slominskii, M.A. Brusentseva, S.V. Kirillov, H.F.M. Schoo, A.V. Vannikov, Russ. J. Electrochem. 40 (2004) 245.

[18] A. Ishchenko, N. Derevyanko, Y.P. Piryatinskii, A. Verbitsky, D. Filonenko, S. Studzinsky, Mater. Sci. 20 (2002) 5.

[19] A.R. Tameev, A.V. Vannikov, H.F.M. Schoo, Thin Solid Films 451-452 (2004) 109.

[20] F. Nüesch, A. Faes, L. Zuppiroli, F. Meng, K. Chen, H. Tian, J. Mater. Sci. 40 (2005) 1353.

[21] F. Nüesch, G. Tornare, L. Zuppiroli, F. Meng, K. Chen, H. Tian, Solar Energy Mater. Solar Cells 87 (2005) 817.

[22] F. Meng, K. Chen, H. Tian, L. Zuppiroli, F. Nuesch, Appl. Phys. Lett. 82 (2003) 3788 .

[23] F. Meng, J. Hua, K. Chen, H. Tian, L. Zuppiroli, F. Nüesch, Proc. SPIE Int. Soc. Opt. Eng. 5938 (2005) 284.

[24] M.E. Peover, Electroanalyt. Chem. 2 (1967) 42.

[25] S.-S. Sun, Solar Energy Mater. Solar Cells 85 (2005) 261.

[26] N.S. Saricitci, Mater. Today 7 (9) (2004) 36.

[27] S. Walheim, M. Böltan, J. Mlynek, G. Krausch, U. Steiner, Macromolecules 30 (1997) 4995. 